\title{
A CIRCULAÇĀO ATMOSFËRICA REGIONAL E AS FAMÍLIAS DE TIPOS DE TEMPO IDENTIFICADAS NA REGIĀO CENTRAL DO RIO GRANDE DO SUL
}

Maria da Graça Barros Sartori

Departamento de Geociências. Centro de Ciências Naturais e Exatas. UFSM. Santa Maria, RS.

\section{RESUMO}

A anālise da atuação dos sistemas atmosfēricos, na região central do Rio Grande do Sul, possibilitou a individualização dos di ferentes tipos de tempo a eles associados, resultantes de formas de comportamento diversas dos elementos meteorológicos e obtidas atra vēs da tēcnica de anālise rītmica. Os padrões identificados, em nū mero de quinze, tornaram possível o estabelecimento de três grandes famīlias de tipos de tempo em função das respostas fornecidas pelos elementos atmosféricos ao avanço e domínio, na região, dos sistemas extratropicais, dos intertropicais ou dos seus mecanismos instabili zadores do tempo.

\section{SUMMARY}

SARTORI, M.G.B., 1981. The regional atmospheric circulation and weather family types identified at the central region of Rio Gran de do SuT. Ciência e Natura (3):101-110

The analysis of the action of the atmospheric systems in the central region of Rio Grande do Sul made possible the individuation of the various types of weather associated to them, resulting from various behavioural patterns. The patterns were obtained through the tecnique of rhythmic analysis. The identified patterns, numbering fifteen, made the establishment of three big families of types of weather possible as a result of the plotted responses from atmospheric elements due either to the advance and dominance of the extra-tropical systems in the region, or to the inter-tropical systems, or to their un-stabilizing mechanisms over the weather.

INTRODUÇAOO

Em estudos anteriores, realizados na região de Santa Maria $(2,3)$, buscamos definir a gênese dos estados atmosféricos, atravēs da anālise dos mecanismos de circulação à nĩvel continental (escala zonal), para verificar a organização climática do espaço geogrāfico gaúcho. Dessa etapa resultou uma avaliação para o ano de 1973 da par ticipação dos sistemas meteorológicos extratropicais e intertropicais (SARTORI, 3) geradores dos diversos tipos de tempo na escala regio nal e/ou local. 
0 presente trabalho está intimamente relacionado aos ante riores, visto tratar-se da primeira definição de tipos de tempo pa ra a região central do Rio Grande do Sul, sō possîvel de ser obtida por estar baseada na anälise da circulação dos sistemas atmosféricos e na resposta que o espaço regional oferece à atuação desses siste mas.

Salientamos, porēm, que não se trata de uma classificação climática para o Rio Grande do Sul, pois segundo MONTEIRO (1) não se pode "... atingir o todo espacial a partir das propriedades extens $\underline{j}$ vas locais..." pois estas estão comprometidas quantitativamente com os fatores de natureza local.

0 resultado da ação dos sistemas atmosfēricos levou-nos por tanto, a propor familitias de tipos de tempo, uma vez que estes alter nadamente se associavam aos sistemas extratropicais, aos intertropi cais ou às correntes perturbadoras a eles vinculadas.

Embora sendo uma análise de caräter climatolōgico, não de xa de ser também importante do ponto de vista geogräfico, pois a atmosfera desempenha papel de insumidor energético, juntamente com a energia solar, em todo sistema ambiente organizado. Nesse tipo de sistema representado, no caso, pela organização do espaço regional, os insumos climāticos são importantes no jogo das relações de cará ter geográfico e do qual participam, também, a organização social e econômica. Nesse sentido destacamos que "o bom funcionamento do sis tema econōmico, a interpretação de sua validade a longo prazo e os efeitos das decisões tomadas devem estar referenciadas ao espaço am biente dentro do qual operam". (TAYLOR in MONTEIRO, 1).

Por outro lado, segundo MONTEIRO (1) "a atmosfera passou a ser reconhecida como um recurso vital básico e o clima, pela pró pria dinâmica de sua essência física, como um insumidor energético ativando o ambiente por suas variações temporais, e através de suas associações com os demais componentes naturais, ajudando a definir a estrutura do espaço ambiente e sua organização funcional".

sendo assim, a definição e caracterização dos diversos es tados da atmosfera - tipos de tempo - que ocorrem na região central do Rio Grande do Sul vem de encontro a essas preocupações, visto es tarem associados aos sistemas atmosféricos de maior atuação no espa ço regional organizado, conforme comprovado por SARTORI (3).

\section{A METODOLOGIA E O MATERIAL UTILIZADO}

Com o intuito de verificar as respostas fornecidas pela re gião de Santa Maria à circulação atmosfērica a nĩvel continental, cú ja dinâmica se caracteriza pelo confronto e/ou domínio dos diversos sistemas meteorolōgicos, procuramos individualizar as diversas for 
mas de encadeamento dos elementos climáticos ao longo do ano de 1973 , eleito como representativo do habitual para a referida região (SAR TORI, 2).

0 estudo foi realizado, como os anteriormente citados, com base na observação dinâmica dos estados atmosféricos. A partir des sa ordem de idéias, lançamos mão da anālise rítmica realizada atra vés da sequência contínua de cartas sinóticas e de dados detalhados dos elementos climáticos da região focalizada. Na anālise do compor tamento da circulação atmosférica utilizamos as cartas sinōticas das 12:00 GMT obtidas em microfilme, junto ao Instituto Nacional de Me teorologia no Rio de Janeiro. Para as respostas locais e/ou regio nais à ação dos sistemas meteorológicos nos valemos de dados de pres são, umidade relativa, temperatura, precipitação, nebulosidade, ven to e outros fenōmenos relativos a Santa Maria, São Gabriel e Jūlio de Castilhos, obtidos junto às estações meteorolōgicas dessas loca lidades e ao 80 Distrito de Meteorologia, sediado em Porto Alegre.

Do encadeamento sequencial e simultâneo entre o comporta mento dos elementos e sistemas meteorológicos atuantes, resultaram padrões de comportamento distintos desses elementos possibilitando a definição de 15 tipos de tempo, reunidos em 3 grandes famīlias, com certas particularidades que os individualizam e que são caracterís ticas de cada sistema atmosférico.

Ressaltamos que a nomenclatura utilizada para cada tipo de tempo ē o resultado de observações e conclusões prōprias, visto não existir terminologia climatológica oficial a esse respeito, jā que os estudos dessa natureza no Brasil são especialmente esparços, re fletindo realidades diferentes no que se refere a circulação atmos férica. Assim, como o espaço territorial brasileiro é vasto não há ainda uniformidade de vocabulārio para designar os tipos de tempo.

\section{RESULTADOS E DISCUSSAO}

No decorrer da anālise rítmica comparativa, comentada ante riormente, foi-nos possível identificar as seguintes famīias de tị pos de tempo:

TEMPOS ANTICICLONATS POLARES

Tempo Anticiclonal Polar Típico

E um tipo de tempo caracterizado por altas pressões, moti vadas pelo estabelecimento do Anticiclōnico Polar sobre a região. $\underline{A}$ presenta ventos leves, muitas calmas, abaixamento significativo das temperaturas mīnimas, cēu limpo, orvalho e geada ou nevoeiros à noi te e pela manhã. Estā associado às Massas de Ar Polares, Marítima ou Continental, individualizadas pela trajetōria do Anticiclone Polar Atlântico pelo oceano ou pelo continente. (Figura 1). 
Tempo Anticiclónico Polar Maritimo

Estā relacionado ao domínio na região de uma tî́pica Massa Polar Atlântica (marítima) com o centro do Anticiclone Polar Atlân tico sobre o oceano, mas prōximo ao continente. Registra de clinio de temperatura, ventos de E, S e SE leves a fracos, pressão em alta, mas com valores inferiores ao tipo anterior, e céu limpo que favorece a insolação diāria, provocando temperaturas máximas em ge ral acima de $20^{\circ} \mathrm{C}$. A noite ocorre o orvalho. (Figura 2).

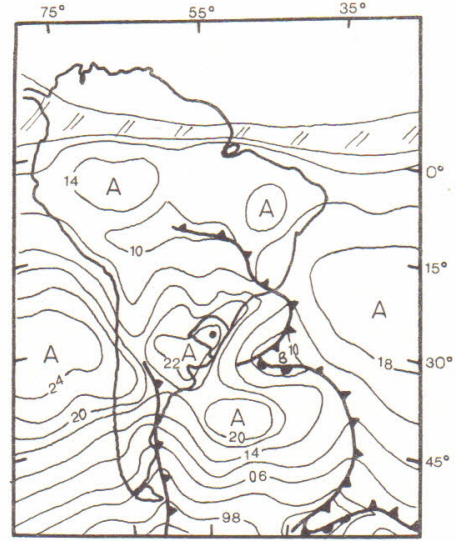

Figura 1. Tempo Anticiclonal Polar Típico em 15/08/73.



Figura 2. Tempo Anticiclōnico Polar Marítimo em 18/05/73.

Tempo Anticiclônico Polar Continental

Associa-se à Massa Polar Continental (trajetória continen tal do Anticiclone Polar Atlântico) que no inverno atinge muitas ve zes a região, trazida pelo reforço do abastecimento polar oriundo da Massa Polar Pacífica. Caracteriza-se por ventos de W, SW e NW, tem peraturas mínimas de $0^{\circ} \mathrm{C}$ ou menos, alta pressão, umidade relativa mais ou menos baixa, mas inferior aos valores registrados no Antici clōnico Polar Marítimo. Quando os ventos são leves ocorrem fortes gea das. E o tipo de tempo que registra as menores temperaturas. (Figu ra 3 ).

Tempo Anticiclônico Polar Pós-Frontal

Mais comum no inverno, ocorre logo após a passagem da Fren te Polar Atlāntica sobre a região, encontrando-se jā ao norte do es tado ou em Santa Catarina.

Caracteriza-se por ventos de E e SE moderados a fortes, céu encoberto com chuvas, neblina ou nevoeiro, pressão baixa em relação aos dias anteriores e posteriores e pequena amplitude térmica motị vada pela alta nebulosidade. Em geral associado à Massa Polar Attān 
tica que traz ar úmido do oceano o que favorece a ocorrência de ne voeiros sobre a superfície jā resfriada.

Tempo Anticiclônico Polar em Tropicalização

Está ligado à Massa Polar Velha registrando altas tempera turas (máx. $>25^{\circ} \mathrm{C}$ ), ressecamento do ar, declínio da pressão, céu limpo, ventos variāveis e calmas e orvalho. Quando em fase pré-fron tal ocorrem chuvas provocadas por Instabilidades de Noroeste e Ca lhas Induzidas definindo-se os fluxos de W, NW, N e SW até muito for tes, com umidade relativa de atē $45 \%$. (Figura 4 ).

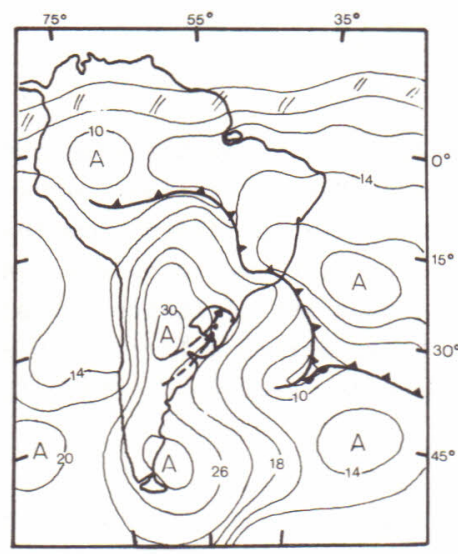

Figura 3. Tempo Anticiclónico Polar Continental em 18/07/73.

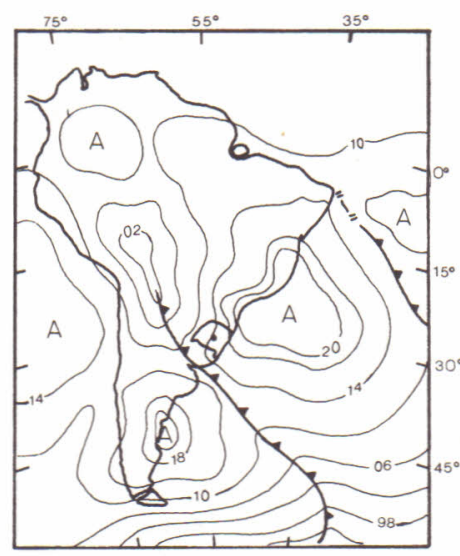

Figura 4. Tempo Anticiclōnico Polar em Tropicalização em 4/10/73.

Tempo Anticiclonal Aquecido

E uma variação do Tempo Anticiclonal Típico motivado pelo aquecimento e consequente enfraquecimento do Anticiclone Polar Atlân tico devido a continentalização do mesmo. E um tipo de tempo carac terizado pela presença do centro do Anticiclone Polar Atlântico so bre a região e associado à Massa Polar Velha, registrando elevação moderada da pressão (inferior ao típico), ceú limpo, ventos leves e calmas, e provocando aumento das temperatıras máximas e declínio das mînimas, porém, ambas mais elevadas que no Tempo Anticiclonal Típico.

\section{TEMPOS ASSOCIADOS A SISTEMAS INTERTROPICAIS}

Tempo Anticiclônico Tropical Maritimo

Relaciona-se ao domīnio na região da Massa Tropical Atlân tica (marítima) que origina tempo bom com fluxos predominantemente de $\mathrm{NE}$ e E leves, temperaturas elevadas (entre $19^{\circ} \mathrm{C}$ e $35^{\circ} \mathrm{C}$ ), céu 1 impo, ressecamento gradativo do ar e orvalho. Em geral, tem duração efême ra, isto é, no máximo dois dias em virtude de anteceder a chedada da 
Frente Polar Atlântica. (Figura 5).

Tempo Anticiclônico Tropical Continentalizado

Este tipo de tempo se individualizou por estar relaciona do à Massa Tropical Atlāntica que sofreu os efeitos do aquecimento continental, descaracterizando-a. Isto acontece quando o setor oeste do Anticiclone Tropical Atlāntico avança sobre o continente, passan do a massa de ar, originalmente marítima, a se comportar como conti nental. Apresenta temperaturas elevadas (nunca inferiores a $30^{\circ} \mathrm{C}$ ), pressão baixa (1010 à $1013 \mathrm{mb})$, ressecamento do ar $(43 \%$ a $58 \%)$, flu xos de $N, N E$, NW e W variāveis, céu limpo e Calhas Induzidas. (Figu ra 6$)$.

Tempo Depressionârio Continental

Está associado ao aprofundamento da Baixa do Chaco que con segue atingir a região atravēs da descida da Massa Tropical Continen tal. Isto origina um tipo de tempo dos mais característicos, com tem peraturas muitas vezes superiores a $35^{\circ} \mathrm{C}$, pressões muito baixas (in feriores às das prẽ-frontais comuns e ao Tempo Anticiclônico Trop $\underline{i}$ cal continentalizado), umidade relativa baixa devido à forte insola ção e fluxos do quadrante oeste de intensidades variāveis. (Figura 7).

TEMFOS ASSOCIADOS A CORRENTES PERTURBADAS

Tempo Frontal de Sudoeste de Atuasão Moderada

Tipo de tempo provocado pela passagem mais ou menos rápida (normal) da Frente Polar Atlāntica, originando chuvas razoāveis (> $30 \mathrm{~mm}$ ) após uma fase pré-frontal com ventos fortes. Não ocorre recuo da Frente Polar e os ventos são variāveis em direção e intensidade, com pequena amplitude térmica. A este tipo de tempo frontal segue-se uma Massa Polar Atiântica. (Figura 8).

Tempo Frontal de Sudoeste de Fraca Atuacão

A este tipo de tempo frontal, tambēm associado a Frente Po lar Atlāntica, se antecede uma fase pré-frontal com ventos fracos e algumas calmas, caracterizando-se pela passagem rāpida da Frente Po lar que, entretanto, recua no dia seguinte para posterior avanço. Neste tipo, as chuvas são leves com pequeno abaixamento das tempera turas. No geral, segue-se uma Massa Polar Velha.

Tempo Frontal Estacionārio

E provocado pela permanência de até 3 dias da Frente Polar Atlântica sobre a região, resultante de fraco fluxo polar, originan do um tipo de tempo muito úmido com chuvas ou nevoeiros, ventos de $E$ e SE geralmente fracos e temperatura em declínio.

Tempo Frontal de Nordeste

Relaciona-se à passagem de uma Frente Quente caracterizan 
do-se por chuvas fortes, relämpagos e trovoadas, baixas pressões em relação aos dias anteriores, ventos variáveis em direção e intensi dade, e pequena amplitude térmica $\left(22^{\circ} \mathrm{C}\right.$ a $\left.27^{\circ} \mathrm{C}\right)$. Em geral antecedi do pelo Tempo Anticiclónico Polar em Tropicalização e precedido pe 1o Tempo Anticiclônico Tropical marítimo ou continentalizado.

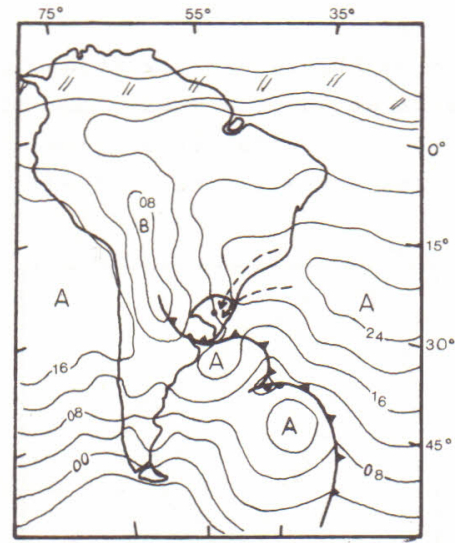

Figura 5. Tempo Anticiclōnico Tropical Marítimo em 11/07/73.

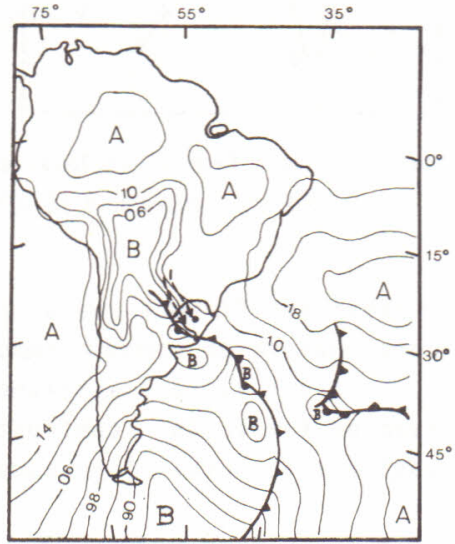

Figura 7. Tempo Depressionārio Continental em 14/12/73

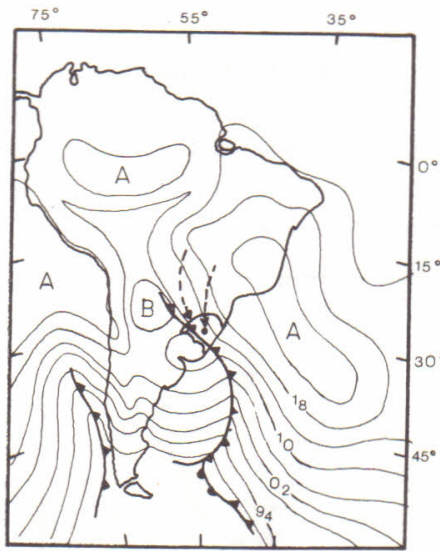

Figura 6. Tempo Anticiclōnico Tropical Continentalizado em 8/07/73.

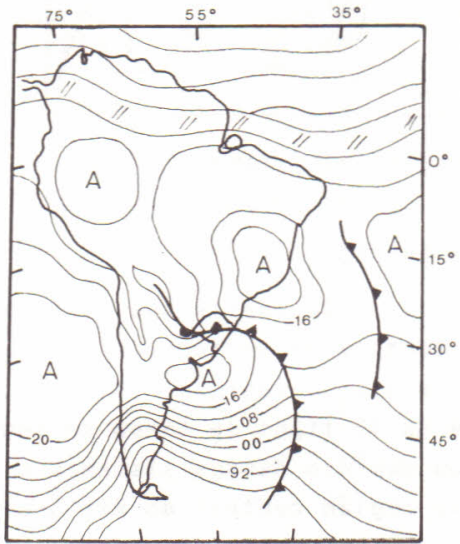

Figura 8. Tempo Frontal de Sudoeste de A.tuação Moderada em 28/05/73.

Tempo Frontal Ciclonal de Atuacão Direta

Este tipo de tempo é provocado pela Frente Polar Atlântica zom ciclogēnese (oclusão) que se encontra mais ou menos sobre a re jião resultando em chuvas fortes $(50-60 \mathrm{~mm})$, ventos do quadrante les 
te até meio fortes, céu totalmente encoberto, pressão baixa em compa ração aos dias anteriores e temperaturas mais ou menos estáveis com relação a fase pré-frontal. E um tipo de tempo chuvoso ao qual pre cede uma Massa Polar Atlântica ou Massa Polar Velha, de acordo com a época do ano. (Figura 9).

Tempo Frontal Cielonal de Atuação Indireta

Acontece quando a Ciclogênese da Frente Polar Atlântica estā no oceano, na latitude do Rio Grande do Sul e Uruguai, com ape nas o ramo continental afetando a região; esta situação origina chu vas escassas, grande nebulosidade e ventos variāveis de moderados a fortes. (Figura 10).

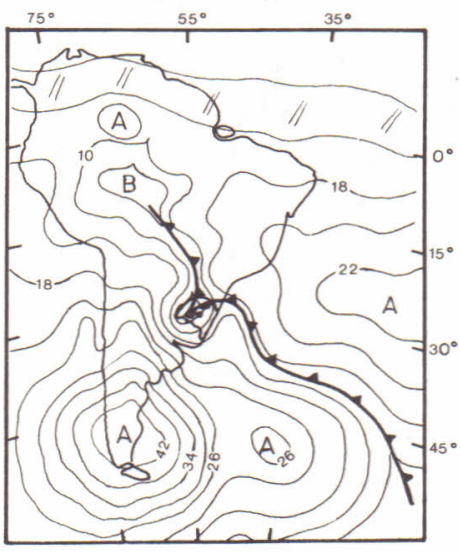

Figura 9. Tempo Frontal Ciclonal de Atuação Direta em 16/10/73.

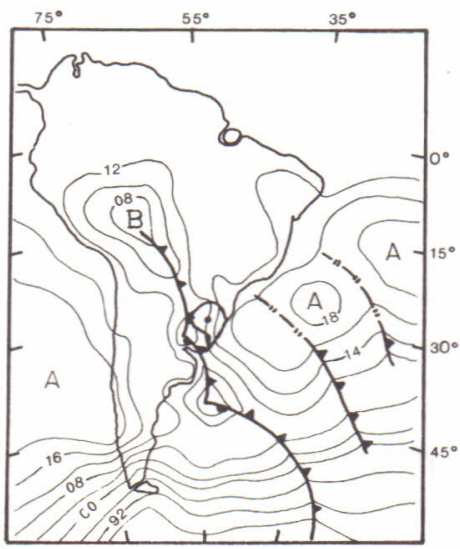

Figura 10. Tempo Frontal Ciclonal de Atuação Indireta em 18/3/73.

\section{CONCLUSÖES}

Na anālise da circulação secundāria verificamos quais os sistemas atmosféricos na escala continental que maior controle impõem à circulação regional (SARTORI, 2,3 ) e, a partir disso, constatamos que os 15 tipos de tempo se individualizam em função do confronto e/ou dominio desses sistemas e das respostas diferentes fornecidas pela região central do Rio Grande do Sul.

os tipos de tempo, reunidos em três grandes famílias, se as sociam basicamente: 1) aos sistemas extratropicais com seus mecanis mos frontais instabilizadores do tempo (Frente Polar Atlāntica) e seus avan gos anticiclonais polares de ações estabilizadoras (Massas Polares); 2) aos sistemas intertropicais com seus avangos tropicais maritimos (Massa Tropical Atlāntica) estabilizadores de tempo e suas correntes tropicais continentais (Massa Tropical Continental) com fluxos de 
oeste e noroeste responsāveis, em parte, por fortes aquecimentos pré-frontais, instabilizadores do tempo antes mesmo da passagem fron tal.

Dessa forma, constatamos seis tipos de tempo associados aos avanços anticiclonais polares, individualizados entre si pelas for mas diferentes de comportamento dos elementos meteorológicos, em par te resultantes do posicionamento do Anticiclone Migratório Polar em relação à região (Figuras $1,2,3$ e 4 ).

Associados aos sistemas intertropicais identificamos três tipos de tempo, sendo dois relacionados ao domínio do Anticiclone Tro pical Atlântico com posicionamento mais sobre o oceano (Massa Tropi cal Atlântica) ou abrangendo grande parte do continente (Massa Tro pical Atlântica continentalizada) (Figuras 5 e 6 ) que fornece dife rentes respostas no que se refere ao comportamento dos elementos. 0 terceiro tipo vincula-se à participação da Massa Tropical Continen tal que origina o Tempo Depressionārio Continental caracterizado por altas temperaturas. (Figura 7).

Os estados de tempo associados às correntes perturbadas são em nūmero de seis, estando um relacionado ao avanço da Massa Tropi cal Atlântica continentalizada (Tempo Frontal de Nordeste). Os de mais são resultantes de avanços frontais polares que, dependendo do acúmulo de ar frio no Anticiclone Migratōrio polar e da época do ano, podem facilitar ou não a propagação da Frente Polar Atlāntica. Isto ocasiona tipos de tempo diferentes, principalmente no que se refere ao comportamento da precipitação, em funçã̃o das velocidades de des locamento da Frente, da presença ou não de ciclogêneses e oclusões no seu eixo, e da posição dessas perturbações em relação à região. (Figuras 8, 9 e 10).

Esses tipos de tempo foram identificados na região central do Rio Grande do Sul. Como um sistema meteorológico não age só local mente, mas sempre em espaço bastante amplo (muitas vezes a nível con tinental), acreditamos que se possa extrapolá-1os para as outras re giões do Estado jā que a gênese dos estados atmosféricos é a mesma. Entretanto, temos sempre que considerar e respeitar as peculiarida des locais que podem oferecer respostas diferentes, em termos de va lores, a um mesmo sistema atmosférico atuante.

\section{BIBLIOGRAFIA CITADA}

1. MONTEIRo, C.A.F. o elima e a organizag̃̃o do espaco no Estado de São Paulo: problemas e perspectivas. São Paulo, IGEOG-USP, 1976, Sērie Teses e Monografias nọ 28.

2. SARTORI, M.G.B. O clima de Santa Maria: do regional ao urbano. 
Dissertação de Mestrado, Dep. de Geografia da Faculdade de Fi losofia, Letras e Ciências Humanas da Universidade de São Pau 10. São Paulo, 1979. 169 p.

3. SARTORI, M.G.B. Balanço sazonārio da participação dos sistemas atmosfēricos em 1973, na região de Santa Maria, RS. Ciência e Natura (2):41-53, 1980 .

Recebido em agosto, 1981; aceito em dezembro de 1981. 